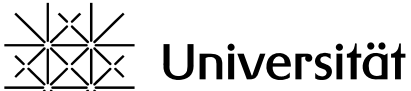 Basel
}

Wirtschaftswissenschaftliche Fakultät

\section{Dealing with Supply Disruptions on the European Natural Gas Market: Infrastructure Investments or Coordinated Policies?}

Universität Basel

Peter Merian-Weg 6 4052 Basel, Switzerland wwz.unibas.ch
Corresponding Author:

Prof. Hannes Weigt

Forschungsstelle Nachhaltige Energie- und Wasserversorgung

Tel: +41 (0) 612072460

Mail: hannes.weigt@unibas.ch 


\title{
Dealing with Supply Disruptions on the European Natural Gas Market: Infrastructure Investments or Coordinated Policies?
}

\author{
Jan Abrell $^{(\mathrm{a})}$, Leo Chavaz $^{(\mathrm{b})}$, Hannes Weigt ${ }^{(\mathrm{b})}$
}

(a) Center for Energy and the Environment (CEE), ZHAW, Winterthur, Switzerland

(b) Forschungsstelle Nachhaltige Energie- und Wasserversorgung, University of Basel, Basel, Switzerland

\section{Corresponding author:}

Hannes Weigt

Forschungsstelle Nachhaltige Energie- und Wasserversorgung

Wirtschaftswissenschaftliche Fakultät der Universität Basel

Peter Merian-Weg 6, Postfach, CH-4002 Basel

Tel: +41 (0)61 207 3259, Mail: hannes.weigt@unibas.ch

Web: http://www.sccer-crest.ch/ and http://fonew.unibas.ch/

\begin{abstract}
$\underline{\text { Abstract: }}$
Natural gas plays an important role in many European energy systems especially with regard to the envisioned transition towards a less carbon intensive energy supply. Being dependent on imports especially from Russia - this raises questions about the future development and security of Europe's gas supply. Using a numerical network model of the European gas system we assess 1) the potential impact of infrastructure extensions for Europe's gas supply and 2) the role of supply security policies in coping with a disruption of Russian imports via the Ukraine. Our results indicate that overall the European gas infrastructure is sufficient for average market conditions. Due to the strong dependency on Russian imports, however, disruptions during the winter months could lead to load curtailment. Projected network extension (Southern Gas Corridor, Nord Stream 2, and new LNG terminals) or a strategic storage policy coordinated across Europe has the potential to reduce this shortage. The positive impact of an extended network, however, also depends on the capability of the global gas market to provide flexible gas that can be reallocated towards Europe. The majority of demand curtailment can already by countered by a relatively modest amount of strategic storage (20\% to $30 \%$ ) if their use during crisis situations is coordination across European countries.
\end{abstract}

Key words: $\quad$ Europe, natural gas, North Stream, network model, storage, supply security

Acknowledgements: This research has been carried out as part of the project 'Modelling the Swiss Gas Market in a European Context'; financed by the Swiss Federal Office of Energy Research Programme Energy-Economy-Society (EWG) and within the framework of SCCER CREST (Swiss Competence Center for Energy Research, www.sccer-crest.ch), which is financially supported by the Innosuisse under Grant No. 1155002547. A preliminary version of this paper has been presented at '13th International Conference on the European Energy Market (EEM)' and has been published in the conference proceedings as: J. Abrell, L. Chavaz and H. Weigt, (2016) "Pathways for the European natural gas market" 


\section{Introduction}

Disruptions in natural gas deliveries are a prominent concern in Europe. As natural gas reserves are geographically concentrated in a few countries and since its supply is vulnerable to network constraints, the market is exposed to supply insecurity. Furthermore, recent geopolitical events have exacerbated this concern. These events notably include the disputes between Russia and Ukraine in 2006 and 2009, as well as the political and economic sanctions imposed by the European Union (EU) against Moscow in response to the ongoing Ukrainian crisis. With more than $15 \%$ of the gas consumed by Europe transiting through Ukraine (IEA, 2015a), the relation between Eastern Europe and Russia is crucial for the European energy security. Moreover, from a European perspective, three ongoing processes and trends further stimulate the need for the study of the gas security. First, the European market is still subject to a restructuring process leading to a reorganization of the market. Second, as numerous domestic producers are exhausting their reserves, Europe is increasingly reliant on imports. Last, the globalization of the gas market offers more diversified supply options, notably through liquefied natural gas (LNG). At the same time, the increasing worldwide demand and the US shale gas boom are redefining international gas trade.

Against this background, the European Union launched the Energy Security Strategy (EC, 2014a) seeking to achieve a twofold goal: first, ensuring short-term resilience of the natural gas network in cases of supply interruption and, second, reducing the dependency on unstable routes and suppliers in the long term. The development of the European pipeline and LNG infrastructures is one of the key measures to achieve a secure supply. In parallel, Moscow aims at reducing its own dependency on Ukraine for its exports towards Europe, thus promoting alternative infrastructure projects.

Stress tests imposed by the European Energy Security Strategy accompany these studies. These tests quantify the impacts of (short-term) supply disruption of either Ukrainian routes or Russian exports in total for a duration of one or six months (EC, 2014b). The related report underlines the large share of demand which cannot be satisfied in the most severe scenarios, notably in Eastern Europe. As a conclusion, the Commission suggests additional measures to enhance the security of supply (SoS) focusing among others on network enhancement, storage optimization, and, in particular, the need for storage usage coordinated across member states.

In this context, the present study seeks to address the aforementioned concerns by developing a numerical model of the European natural gas market. The model shall then be used for conducting scenario analyses of possible future developments. Specifically, we simulate projections of the European natural gas market in 2030 and study the impact of major infrastructure projects (additional pipelines, new LNG terminals, etc.). Subsequently, we test how the system can cope with a Russian supply disruption under different infrastructure and storage policy settings.

The remainder of this paper is structured as follows. The next section presents a short literature review, while section 3 describes the underlying model and dataset. The scenario description and results are structured along two lines: the general long term market evolution is assessed in Section 4 while the analysis of different supply security aspects is provided in Section 5. Section 6 concludes. 


\section{Literature}

The present work draws on an abundant literature studying energy markets, and the natural gas one in particular. We present thereafter a brief introduction of some of the main literature directions related to the paper at hand, namely natural gas system modeling, model bases gas market assessments and scenarios, further security of supply studies, and the linkage of storage and supply security.

There is vast literature on modeling of energy markets (e.g. energy system models including natural gas as fuel) and direct natural gas systems and network models. Holz (2009) provides a detailed review of models applied to the natural gas market. Our model approach builds upon this literature and makes use of a partial equilibrium formulation. This class of model is widely used in policy analysis as well as in energy and environmental economic research. Several partial equilibrium models of the natural gas market can be found in the literature. The Global Gas Model (Egging et al., 2010; Holz et al., 2013), which is one of the most prominent example, is based on a Mixed Complementarity Problem (MCP), and adopts a detailed formulation of the natural gas supply chain. The model comprises technical details on the production sector, the pipeline and LNG transport as well as the storage ones. It further considers a disaggregated demand. The model developed by Neumann et al. (2009) follows a roughly similar structure, however based on non-linear optimization. It focuses on the European market only, and accounts for a single demand sector. Other models which can be found in the literature are notably the NatGas (Zwart and Mulder, 2006), which includes investment in production capacity and a resource constraint, or the TIGER (Lochner, 2011), a cost-minimizing model based on a detailed representation of the European pipeline system. Finally, Abrell and Weigt (2012, 2016a) develop a MCP-based model combining both the electricity and the gas sectors.

Energy market models are applied to simulate possible future developments of the gas market or to address issues like the security of supply ( $\mathrm{SoS})$. Consequently, several studies evaluate supply security of energy markets and, in particular, the European natural gas market. Richter and Holz (2015), for instance, investigate two short and one long-term Russian export disruption scenarios using the Global Gas Model. Abrell and Weigt (2016b) analyze similar scenarios putting the focus on the interaction between the natural gas and electricity market. They highlight the importance of LNG to replace Russian imports, and identify important pipeline extensions to secure the European supply. Dieckhöner et al. (2013) use the TIGER model to evaluate different demand and infrastructure scenarios, in particular the Nord Stream 2 or the Nabucco pipeline. They conclude that, despite remaining bottlenecks in the system, the European natural gas market will be well integrated by 2019 . Finally, Paltsev (2014) analyzes possible developments of Russian gas exports until 2050 using the EPPA model, a computable general equilibrium model of the world economy. Regarding exports to Europe, he states that the need for additional pipeline connections is only justified if Russia wants to diversify its export routes and reduce its dependency on Belarus and Ukraine.

In parallel, as part of the new European Energy Security Strategy, stress tests were launched in 2014 by the EU. These tests simulate the impact of a supply disruption of either the Ukrainian routes or of all Russian exports during one or six months (EC, 2014b). The report underlines the large share of 
demand which cannot be satisfied in the most severe scenarios, notably in Eastern Europe. As a conclusion, the Commission suggests additional measures to enhance the SoS, focusing among others on network enhancement and storage optimization, and stresses the need for more cooperation between member states. Finally, the ENTSO-G recently published the first European Union-wide study on the simulation of gas supply and infrastructure disruption scenarios (ENTSO-G, 2017). Their study is based on a detailed technical model of the European gas system. They identified 17 risk scenarios for the European gas system and simulated them for three different cases of demand. Their results are aligned with previous ones, and underline some of the main dependencies in Europe - e.g. Bulgaria, Romania and Greece are highly vulnerable to disruption of the Russia-Ukraine route or Finland and the Baltic states to interruption of their Russian supplies.

The literature addressing the security of European gas supply is not limited to modeling. Stern (2002) addresses the issue of SoS in a newly liberalized European gas sector on a conceptual level. He adopts a rather optimistic stance of view, and advocates a framework of security standards and obligations at the European level. More pessimistic conclusions are drawn by Correlje and Van der Linde (2006), who analyze the geopolitical factors surrounding the SoS. They conclude to an increasing likelihood of events affecting the European energy supply, and appeal for the development of energy security related policies at the EU level. Le Coq and Paltseva (2009) develop an index assessing the security of European oil, gas and coal imports, notably based on their diversification, the political risks of the exporting countries or the economic impact of a supply disruption. Finally, Costantini et al. (2007) compare various energy scenarios, and identify the growing import dependence of Europe as well as possible collusion amongst suppliers as the main threats for the EU's SoS. Future perspective of European natural gas security are also regularly discussed. In a recent effort, Ruble (2017) discusses the potential positive impact of offshore gas resources in Eastern Mediterranean on European imports. The paper advocates the construction of the East Med pipeline to capitalize on this potential.

Finally, the relation between storage and SoS is also a focus of several studies. Austvik (2004) views the uncertainty surrounding import-dependent countries as a negative externality of the energy consumption, and considers flexibility as a means to mitigate it. The author advocates strategic gas reserves in order to limit price spikes due to supply disruptions. Using a game-theoretical framework, Morbee and Proost (2010) study the incentives of Gazprom to default on its European exports contracts. They consider the European investments into strategic storage as an alternative to the "unreliability" of Russian supply. Their game yields investment into storage as a function of the likelihood of Russia defaulting on its export obligations. Chaton et al. (2009) develop a theoretical framework where precautionary storage is used to countervail a possible future supply disruption. Finally, Ejarque (2011), using a roughly similar setting, evaluates the impact of gas storage restrictions on the profitability of storage operators. The author concludes to significant negative impacts of strategic reserves, notably applying the model to the Italian and Danish examples. 
The paper at hand links and adds to those studies by developing a model approach capable of analyzing European natural gas system conditions and applying this within the context of a supply security assessment focusing on infrastructure and storage policy approaches.

\section{Model and Data}

Following existing literature on gas market modeling, we develop a numerical model representing the European natural gas market embedded into the global market to assess potential developments and evaluate its supply security. The present research effort draws on an abundant literature studying natural gas systems. We use a partial equilibrium framework to represent the behavior of different actors. The model comprises technical details of the production sector, natural gas storage, and the transmission system including the pipeline and LNG transport system. Furthermore, industry and household demand is separately modeled. In the following sections, we present the mathematical model structure and the underlying dataset.

\subsection{Model Formulation}

Our model is based on partial equilibrium settings that we subsequently reformulate as a welfare optimization problem. We notably draw on Abrell and Weigt (2012), Egging et al. (2010) and Neumann et al. (2009) for our model formulation.

The model depicts the action of the various market participants along the natural gas supply chain representing each country as a node in the natural gas system: ${ }^{1}$

- Producers extract natural gas, and sell it on the wholesale market given extraction costs and production capacity constraints.

- LNG operators buy natural gas in a country which possesses liquefaction infrastructure, transport it overseas on a carrier and re-sell it to a country with a regasification infrastructure. They are constrained by the liquefaction and regasification capacities of the respective countries.

- Pipeline operators transport natural gas across borders accounting for transport costs and capacity restrictions of pipeline.

- Gas storage operators arbitrage between different time periods buying and selling gas from and on the wholesale market with capacity constraints on withdrawal, injection and the total amount of storage.

- Demand for natural gas stems from residential consumers, industrial and transformation sectors. Residential consumption is mainly driven by heating, industrial demand by heating and process gas. The transformation sector uses gas for electricity generation and district heating. All three types of consumers are characterized by distinct demand elasticities.

\footnotetext{
${ }^{1}$ According to the perfect competition premises, all actors take prices as given.
} 
For the present work, we assume that all market actors are perfectly competitive allowing us to aggregate the overall cost and benefits into a single welfare objective:

$\max \mathrm{W}=$



Total welfare is represented by two blocks: The first term represents the gross consumer surplus, defined by the area below the respective demand functions. We assume a linear demand-price relation defined for each of the three sectors $i$ (domestic, industry, transformation), country (or node) $n$ and month $t$ of the form: $D_{\text {nit }}=a_{\text {nit }}+b_{\text {nit }} P_{n t}$

The remaining terms reduce this surplus by the costs of production (X), of LNG (FL) and pipeline transport (FP), and of storage (SO). Production costs are defined as a quadratic function. LNG costs are composed of liquefaction cost $\left(c^{\text {liq }}\right)$, route dependent transport cost $\left(\mathrm{tc}^{\mathrm{lng}}\right)$, and regasification cost ( $\mathrm{c}^{\mathrm{reg}}$ ) accounting for the related losses of gas $(\beta)$ needed for the process chain. Pipeline transport is assumed to be subject to a constant cost factor (tc ${ }^{\text {pipe }}$ ) depending on the pipeline length. Finally, storage is subject to a generic cost factor on the stored gas volume $\left(\mathrm{c}^{\text {sto }}\right)$.

The problem is completed by a set of constraints representing the extraction capacities of producers:

$$
\operatorname{cap}_{\mathrm{n}}^{\mathrm{x}} \geq \mathrm{X}_{\mathrm{nt}}
$$

The technical capacities of pipelines:

$$
\operatorname{cap}_{\mathrm{n} \tilde{n}}^{\text {pipe }} \geq \mathrm{FP}_{\mathrm{nnt}}
$$

LNG regasification and liquefaction infrastructure:

$$
\begin{gathered}
\operatorname{cap}_{\mathrm{n}}^{\text {reg }} \geq \sum_{\widetilde{\mathrm{n}}}^{\mathrm{N}}\left(1-\beta^{\mathrm{reg}}\right)\left(1-\beta_{\widetilde{\mathrm{n}}}^{\operatorname{lng}}\right) \mathrm{FL}_{\widetilde{\mathrm{n}} \mathrm{t}} \\
\operatorname{cap}_{\mathrm{n}}^{\text {liq }} \geq \sum_{\widetilde{\mathrm{n}}}^{\mathrm{N}} \mathrm{FL}_{\mathrm{n} \tilde{\mathrm{n}} \mathrm{t}}
\end{gathered}
$$

Technical restrictions on storage use (injection capacity, withdrawal capacity, and maximal working gas capacity):

$$
\begin{gathered}
\operatorname{cap}_{\mathrm{n}}^{\text {in }} \geq \mathrm{SI}_{\mathrm{nt}} \\
\operatorname{cap}_{\mathrm{n}}^{\text {out }} \geq \mathrm{SO}_{\mathrm{nt}} \\
\operatorname{cap}_{\mathrm{n}}^{\text {sto }} \geq \mathrm{STO}_{\mathrm{nt}}
\end{gathered}
$$

A storage balance further links the current and previous month storage levels:

$$
\mathrm{SI}_{\mathrm{nt}}-\mathrm{SO}_{\mathrm{nt}}=\mathrm{STO}_{\mathrm{nt}}-\mathrm{STO}_{\mathrm{n}, \mathrm{t}-1}
$$


The market clearing condition for each node, i.e., country, is given as:

$$
\begin{gathered}
\mathrm{X}_{\mathrm{nt}}+\sum_{\widetilde{\mathrm{n}}}^{\mathrm{N}}\left(1-\beta^{\mathrm{reg}}\right)\left(1-\beta_{\widetilde{\mathrm{n}}}^{\mathrm{lng}}\right) \mathrm{FL}_{\widetilde{\mathrm{n}} \mathrm{t}}+\sum_{\widetilde{\mathrm{n}}}^{\mathrm{N}}\left(1-\beta_{\widetilde{\mathrm{n}}}^{\text {pipe }}\right) \mathrm{FP}_{\widetilde{\mathrm{n}} \mathrm{t}}+\mathrm{SO}_{\mathrm{nt}} \\
=\sum_{\widetilde{\mathrm{n}}}^{\mathrm{N}} \mathrm{FP}_{\mathrm{n} \widetilde{\mathrm{n}}}+\sum_{\widetilde{\mathrm{n}}}^{\mathrm{N}} \frac{\mathrm{FL}_{\mathrm{n} \tilde{\mathrm{n}}}}{1-\beta^{\text {liq }}}+\mathrm{SI}_{\mathrm{nt}}+\sum_{\mathrm{i}}^{\mathrm{I}} \mathrm{D}_{\mathrm{nit}}
\end{gathered}
$$

This market clearing condition represents the basic flow conservation constraint, stating that the quantity of gas produced, imported or taken out of the storage at a node (left hand side) has to be equal to the quantity that is exported, injected into the storage and directly consumed at the node (right hand side). The model also accounts for the gas losses occurring during LNG liquefaction ( $\left.\beta^{\text {liq }}\right)$, regasification $\left(\beta^{\text {reg }}\right)$ and transport $\left(\beta_{n \widetilde{n}}^{\text {lng }}\right)$ as well as during pipeline transport $\left(\beta_{n \widetilde{n}}^{\text {pipe }}\right)$

Furthermore, the model takes into account long-term contracts between producers and consumers. Albeit a current trend towards a reduction in their duration (see e.g. Neumann and von Hirschhausen, 2015), these contracts still represent an important share of the European gas imports. Neumann et al. (2015) provide the most thorough database on long-term contracts. These contacted volumes are implemented as minimum total exports for the respective delivering countries as follows:

$$
\sum_{\widetilde{\mathrm{n}}}^{N} \sum_{\mathrm{t}}^{\mathrm{Y}} \mathrm{FP}_{\mathrm{n} \tilde{\mathrm{n}}} \geq \operatorname{expMin} \mathrm{n}_{\mathrm{n}}^{\text {pipe }}
$$

where $\operatorname{expMin}_{\mathrm{n}}^{\text {pipe }}$ represents the total yearly amount of export stipulated in all contracts of country $n$ utilizing the pipeline network. As the model does not trace the origin of the transported gas, we only ensure that the yearly amount a country exports is at least as high as its contractual obligations. The same is implemented for the LNG exports:

$$
\sum_{\widetilde{\mathrm{n}}}^{N} \sum_{\mathrm{t}}^{\mathrm{Y}} \mathrm{FL}_{\mathrm{n} \widetilde{\mathrm{n}}} \geq \operatorname{expMin}_{\mathrm{n}}^{\ln \mathrm{g}}
$$

\subsection{Model Data}

Our model represents the European natural gas market and its transmission system (see Figure 1). European countries ${ }^{2}$ and worldwide main producers are represented as single nodes. Non-European countries are aggregated to regional hubs (e.g. South America). Overall, the model covers roughly $98 \%$ of the total world production and consumption. The model, thus, allows a focused assessment of the European market, while incorporating the global market dynamics and trends.

The European cross-border pipeline infrastructure is derived from ENTSOG (2015), which provides the technical capacity of each pipeline. Multiple pipelines linking two countries are summed to a single synthetic one. The existing European pipeline infrastructure already compromises several reverse flow connections which are included in the respective cross-border connections. Capacities of

\footnotetext{
${ }^{2}$ By European countries we mean the following ones: Austria, Belgium, Bulgaria, Croatia, Czech Republic, Denmark, Estonia, Finland, France, Germany, Greece, Hungary, Ireland, Italy, Latvia, Lithuania, Netherlands, Norway, Poland, Portugal, Romania, Slovakia, Slovenia, Spain, Sweden, Switzerland, Ukraine, United Kingdom
} 
the future projected pipelines are derived from the respective companies' websites. ${ }^{3}$ Eikon (2015) provides comprehensive data on technical characteristics of all regasification and liquefaction plants. Finally, worldwide storage facilities are obtained from Gas Infrastructure Europe (2015a) and Eikon (2015). Cost of pipeline transport are based on OME (2002) and Egging et al. (2008). LNG transport cost are derived from the delivery prices on Eikon (2015). Cayrade (2004) provides liquefaction and regasification costs. Assumptions regarding pipeline and LNG losses are found in Neumann et al. (2009) and Egging et al. (2008).

\section{Figure 1: Stylized model representation of the European natural gas system}

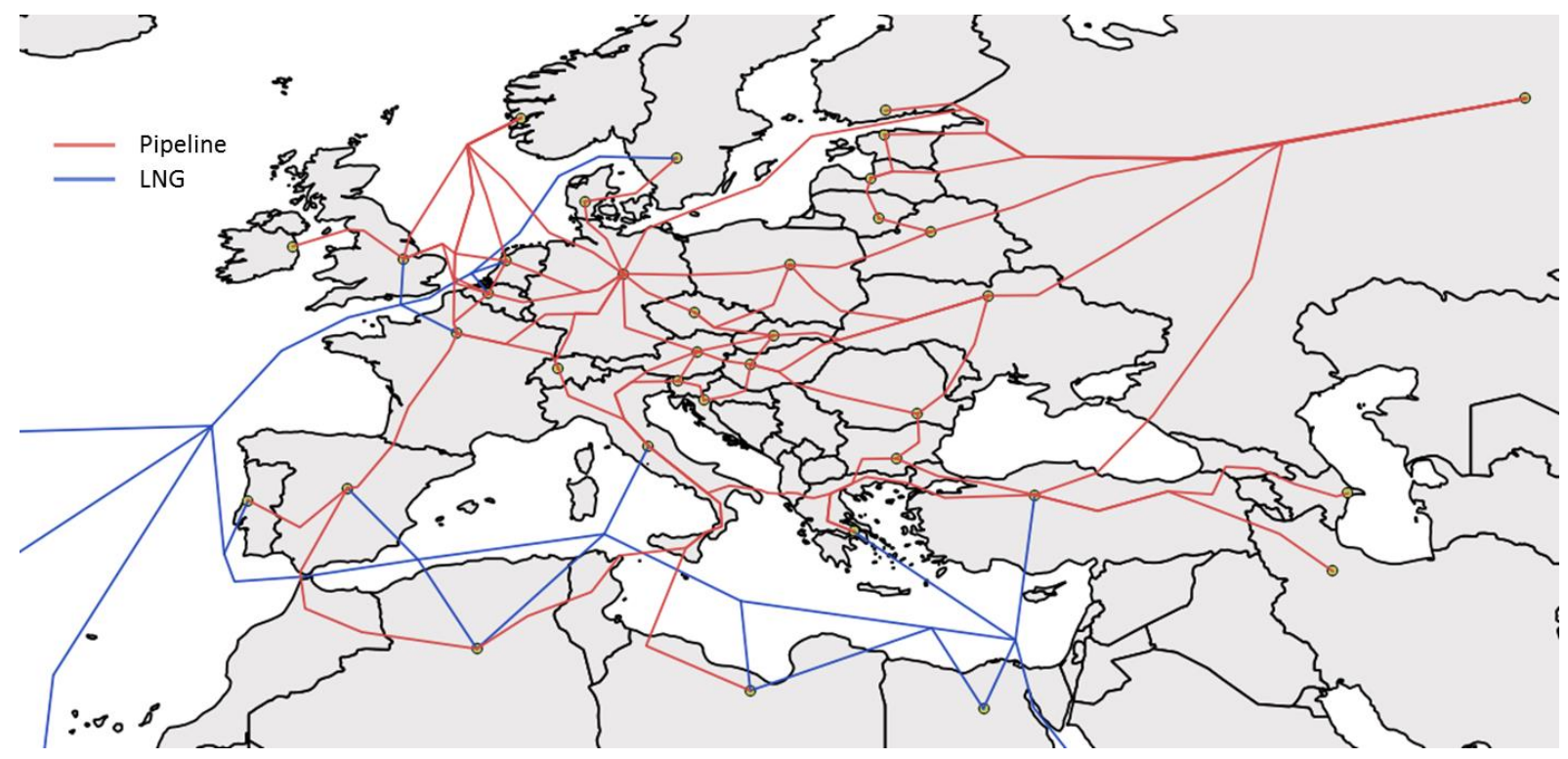

Data on the production capacities of each country is further required for our model. Since reliable information is hard to come by in this domain, we approximated them based on the production patterns. For the countries for which the monthly production is available on Eurostat (2015) or JODI (2015), we assume that each month's production represents $94 \%$ of the respective monthly capacity. ${ }^{4}$ For the rest of the countries, it is assumed that capacity is constant throughout the year, and that each country's highest monthly output represents its extraction capacity. The extraction cost function is derived from OME (2002), Seeliger (2006) and Egging et al. (2008).

Yearly consumption is provided by IEA (2015b). For IEA member states, disaggregated data on consumption of specific sectors is used (domestic, industrial and transformation). For the domestic sector, we generate synthetic monthly profiles by averaging all European countries' domestic consumption patterns, gathered from Eikon (2015). Profiles of transformation users are obtained from

\footnotetext{
${ }^{3}$ Nord Stream: http://www.gazprom.com/about/production/projects/pipelines/ built/nord-stream2/, SGC https://www.tapag.com/the-pipeline \& https://ec. europa.eu/energy/sites/ener/files/documents/pci_7_1_1_en.pdf

${ }^{4}$ This is a fairly common, yet rather arbitrary practice. As it is difficult to come across reliable data on production capacity, most authors assume the capacity based on past production data adding a margin on top. E.g. Egging et al. (2008) use a 10\% margin on past data. The $6 \%$ in our model are also chosen based on the desire to obtain a close fit of production levels to observed market patterns
} 
Eurostat (2015) and JODI (2015), while industrial profiles are calculated by subtracting domestic and transformation ones from the total demand. For the Non-European regional hubs a single consumption sector is implemented.

The linear demand function is calibrated for each node, consumption sector and month based on historic data. Given a reference point - defined by the monthly demand level and the related average spot price - and an assumption about the demand elasticity in this point the two parameters $a$ and $b$ for the demand curve can be defined. We assume a price elasticity of demand of -0.2 for the domestic sector, of -0.4 for the industry and of -0.5 for the transformation one. ${ }^{5}$ Thus, while the reference point varies for each month the demand elasticity is assumed to be same in each month in this reference point. $^{6}$

As we use a linear demand function the respective elasticity is not constant across the whole demand range. The reference price for this elasticity estimate is based on historic spot prices from nine major European and international trading hubs (e.g. Henry Hub in the USA), which are obtained from Eikon (2015). Daily prices are averaged for each month, and each node is linked to the nearest hub. ${ }^{7}$ Countries mostly reliant on LNG exports (e.g. Japan) and not linked to a pipeline trading hub are linked with their regional price of landed LNG, which is also obtained from Eikon (2015). Export countries are assumed to have prices corresponding to the opportunity cost of exporting gas to their main customer. ${ }^{8}$

\subsection{Model Limits and Calibration}

In order to test the suitability of our model for a scenario assessment of the European market, we compare the results of our simulations to historic market outcomes. There are important limitations and shortcomings of the model which need to be considered when comparing the model results with real world observations.

Compared to the other existing gas models referenced in Section 2 our model approach shows the following similarities and differences: Like the World Gas Model (WGM) by Egging et al. (2010) and the TIGER model by (Lochner, 2011) our approach needs to rely on several simplifications. Our depiction of the gas network is similar to the level of detail of the WGM. As we aggregate crossborder pipelines and ignore inner-country pipelines the network representation is inferior compared to the TIGER model. For the supply side, we simplify the formulation of the WGM while preserving its main specifications. We notably aggregate all players into a single representative agent. On the

\footnotetext{
5 For comparison, Egging et al. (2008) use following assumptions: 0.25 for the residential sector, 0.4 for industrial demand and 0.75 for power generation

6 Given the linearity assumption the elasticity in a given point of the demand curve is defined by $\varepsilon_{i}=P_{n t} / b_{n i t} D_{n t}$. Given the reference price $P^{r e f}$ and the reference Demand $D^{r e f}$ the slope $b$ can be calculated for a given elasticity level and used to derive the intercept $a$ of the function. As $P^{r e f}$ and $D^{r e f}$ vary for each also the slope and intercept will vary for each month albeit the elasticity is the same.

${ }^{7}$ Note that despite having the same reference price the different nodes in the model still obtain individual prices representing the national price level in the different scenario runs.

${ }^{8}$ E.g. as Algeria exports a large share of its gas towards Spain, the domestic consumer price in Algeria is assumed to be the one in Spain minus the transport costs to export it from Algeria to Spain.
} 
demand side, we use the same formulation as the WGM thereby having a higher detail than the TIGER model. Finally, as we assume perfect competition we transform the equilibrium model structure into an equivalent optimization formulation for computational reasons. Therefore the final model outlet has many similarities to Neumann et al. (2009).

The simplified inner-country structure likely leads to an overestimation of trading potential and a more equalized price level across European countries as only cross-border and not within-country constraints limit exchange. Furthermore, the assumption of perfect competition is likely to lead to a lower price level (and a subsequent higher demand level) compared to real market outcomes. The European gas market is frequently depicted as a game dominated by a few Cournot players (see e.g. Boots et al., 2004). To capture the impact of those potential deviations we adjust the model parameters. As the underlying cost structure is one of the most uncertain parameter assumptions (due to limited publicly available data for different production sites) the main calibration parameters are markups on those production costs. Within this model calibration priority was given to a match of quantities and global flow patterns and not on a match of model prices with market prices. Consequently the resulting price levels are not directly comparable to real world wholesale price levels and the scenario results should not be seen as market forecasts.

Table 1: Comparison of model results with market observations

\begin{tabular}{l|cc}
\multicolumn{2}{c}{ Market data 2013 } & Model results \\
\hline \multicolumn{2}{l}{ Production by main non-European producers (bcm) } & \\
\hline Algeria & 81.5 & 107.9 \\
Azerbaijan & 16.2 & 18.1 \\
Iran & 164.0 & 161.5 \\
Libya & 11.0 & 13.3 \\
Nigeria & 36.2 & 47.9 \\
Russia & 742.6 & 746.3 \\
\hline \multicolumn{2}{l}{ European demand \& production (bcm) } & \\
\hline Total demand & 594.8 & 635.0 \\
Domestic prod. & 307.7 & 322.0 \\
\hline European shares & & \\
\hline LNG & $7.4 \%$ & $2.1 \%$ \\
Domestic prod. & $45.1 \%$ & $50.7 \%$ \\
Russian pipe. & $35.5 \%$ & $36.3 \%$ \\
Others & $11.9 \%$ & $10.9 \%$ \\
\hline
\end{tabular}

Table 1 displays some of the European market's key values alongside to the corresponding model results. The achieved calibration is far from perfect. Some results are close to reality, for instance for producing countries like Russia, Iran or Libya, while others like Algeria or Nigeria extract more than in reality. One further notices that the LNG share in Europe is significantly underestimated. Overall, our model tends to overestimate demand and supply levels. The European demand exceeds its real value by approximately $7 \%$, while the domestic production is overestimated by roughly $5 \%$. While interpreting the results of our upcoming scenario analyses, one must bear in mind these calibration results. Therefore, the focus of the scenario analysis should be put on the obtained general dynamics and interdependencies and less on absolute values. 


\section{Long-term Market Evolutions}

As a first application of our model, we develop projections of the European natural gas market in 2030. The focus is on the impact of infrastructure extensions as we sketch different pathways for the evolution of European gas infrastructure and evaluate their effect on the market.

We conduct a ceteris paribus approach with respect to underlying cost and price levels and alter production, demand and infrastructure assumptions (i.e., we project the calibrated model with the base year 2013 into the year 2030). The demand and production data are updated based on the New Policies scenario of the World Energy Outlook (IEA, 2015c). Infrastructure assumptions are specified for each pathway. Aside from the relevant projects, we do not assume any further network extension. As we use the 2013 price and cost assumptions for all scenarios the obtained results show the impact of altered infrastructure changes on the resulting market dynamics.

We investigate the following three infrastructure pathways:

1. As-is 2030: assuming that the current infrastructure remains unaltered

2. Main Projects: the infrastructure is completed by some of the currently discussed infrastructure projects:

- The Southern Gas Corridor (SGC): a three-part project consisting of the South Caucasus Pipeline (SCP), the Trans-Anatolian Pipeline (TANAP) and the TransAdriatic Pipeline (TAP) connecting Azerbaijan to Italy through Turkey and Greece. Some portions of the SGC have already been built.

○ The Reverse Flow project: opening of a South-North route from Italy to Germany and Belgium thanks to transformation of the existing pipelines.

- Several additional LNG regasification terminals planned in Europe, notably in Croatia, France, Spain or Sweden.

○ Currently projected developments of the storage infrastructure (e.g. in Germany, France or Italy).

3. Nord Stream 2: same as Main Projects with the addition of the Nord Stream extension, a project which shall double the capacity of Russian exports towards Germany. First agreements for the construction have recently been reached by the commercial partners. It is, however, heavily debated, and Eastern European countries like Poland have engaged in a political and legal battle to fight the project.

\subsection{As-is 2030}

This first pathway can be interpreted as a benchmark to identify the impact of changes in demand and supply on the market, without any change in the infrastructure. Compared to the 2013's levels, the IEA foresees a slightly growing demand level in Europe (a $1 \%$ increase). On a global scale however, both the worldwide demand and production levels are believed to be expanding by more than $30 \%$, mainly owing to the surging demand in Asia and Africa. On the supply side, many European producers are slowly exhausting their gas reserves. Their production is thus forecasted to shrink: $-12 \%$ for Norway 
and up to $-38 \%$ for the United Kingdom or Germany. In reaction to this, on the one hand the share of LNG imports in European consumption increases (amounting to roughly 10\% of the total demand compared to $2 \%$ previously). On the other hand, the share of Russian gas is also rising and takes a value of $40 \%$.

The increasing importance of LNG can also be noticed in the seasonal structure. The impact of gas demand in heating leads to a large difference of consumption between summer and winter months. Currently, this seasonal flexibility is predominantly supplied by storage, while some European producers (mainly Netherlands) and Russia provide complementary supply. The results of the As-is 2030 simulation indicate the rise of LNG as a flexible supplier, allowing to compensate for the declining production of European suppliers and to reduce the Russian imports (see Table 2).

Due both to the diminishing domestic production and due to increasing global demand, the average price level in continental Europe slightly increases by $6 \%$. On the contrary, the price spread between summer and winter declines. This seasonal price pattern is explained by the fact that, in both, summer and winter, the marginal supply determining the market price is provided by LNG imports in 2030 .

\section{Table 2: Contribution to seasonal demand spread}

\begin{tabular}{l|c|c}
\multicolumn{2}{c}{ Baseline 2013 } & As-is 2030 \\
\hline Own extraction & $22.8 \%$ & $15.0 \%$ \\
Storage & $57.1 \%$ & $54.5 \%$ \\
Russia & $20.1 \%$ & $11.3 \%$ \\
LNG & $0.0 \%$ & $19.3 \%$ \\
\hline The results are in relation to the total demand of all modeled European countries.
\end{tabular}

\subsection{Main Projects}

The infrastructure projects that we consider in the Main Projects pathway have the overall effect to enhance import and transport capacity of the European natural gas market. Due to more supply possibilities prices decrease inducing a demand increase of roughly 1\% compared to the As-is 2030 level. Moreover, the SGC pipelines undermine the prevalence of Russian exports (37\% market share), as Azerbaijan enhances its supply to Turkey or to Greece. Surprisingly, the simulation results do not indicate growing LNG imports, although several regasification terminals are added to the European infrastructure. This is primarily explained by the cost disadvantage of LNG compared to the additional import alternatives comprised in Main Projects.

The SGC further leads to a partial reallocation of the Russian flows towards Western Europe, owing to the rising independence of the Southern-Eastern parts of Europe. Overall, a more abundant and cheaper gas supply in Europe results from the new infrastructures. Hence, the average price is slightly reduced compared to As-is 2030. It is further to be noted that, in the simulation, the last branch of the SGC linking Greece to Italy and the Reverse Flow project (from Italy towards Germany and Belgium) are both strongly underused. This highlights the fact that, in the simulation's results, there seems to be sufficient transport and export capacities to supply Western Europe at cheaper costs than through this additional route. 


\subsection{Nord Stream 2}

The extension of the Nord Stream pipeline enhances the availability of cheap Russian gas in Western Europe, thus resulting in a $2 \%$ increase in demand with respect to As-is 2030. The added export capacity permits Russia to increase its market share in Europe, accounting for approximatively $40 \%$ of the demand. Hence, the Nord Stream 2 project countervails the negative impacts of the SGC for Russia. Germany further adopts a pivotal position on the European market by re-dispatching Russian gas towards the rest of the continent. Finally, Nord Stream 2 causes a reduction of the usage of the route over Ukraine ( $-21 \%$ of shipped quantity), thereby depriving the transit countries (e.g. Slovakia, Hungary or Austria) of substantial transit fees. Furthermore, the LNG share in Europe is decreasing, as it is replaced by the more economical alternative of Russian gas.

The price effect of Nord Stream 2 case is stronger than in the Main Projects. The average price reduction compared to the As-is 2030 case amounts to $-6 \%$. The price level returns to its Baseline 2013 level.

\subsection{Comparison}

Comparing our three different pathways with the 2013 simulated results and corresponding market observations, we note the strong reduction of domestic European supply in 2030 (Table 3). How this reduction will be compensated for notably depends on the gas infrastructure. In all pathways, we observe an increase in the LNG share. However, compared to the market results of 2013 this raise may be overestimated in our simulations as we obtain significantly lower LNG shares in our baseline calibration. Nevertheless, LNG is likely to remain an important supplier for Europe, especially for southern countries.

Russian imports remain important for Europe's natural gas market in all scenarios. In the Main Projects case, where the Russian market share is the lowest of all scenarios, it remains at a level which is comparable to today's market. The question of how to cope with this dependency is therefore likely to remain an important element of Europe's energy policy in the next decade.

Table 3: Supply Shares

\begin{tabular}{|c|c|c|c|c|c|}
\hline & $\begin{array}{c}\text { Market } \\
\text { data } 2013\end{array}$ & $\begin{array}{c}\text { Baseline } \\
2013\end{array}$ & $\begin{array}{l}\text { As-is } \\
2030\end{array}$ & $\begin{array}{c}\text { Main } \\
\text { Projects }\end{array}$ & $\begin{array}{c}\text { Nord Stream } \\
\mathbf{2} \\
\end{array}$ \\
\hline Own Extraction & $45.1 \%$ & $50.7 \%$ & $37.6 \%$ & $37.2 \%$ & $36.8 \%$ \\
\hline Russia & $35.5 \%$ & $36.3 \%$ & $40.2 \%$ & $37.4 \%$ & $40.2 \%$ \\
\hline Other pipes & $11.9 \%$ & $10.9 \%$ & $12.9 \%$ & $16.3 \%$ & $16.1 \%$ \\
\hline LNG & $7.4 \%$ & $2.1 \%$ & $9.3 \%$ & $9.0 \%$ & $6.9 \%$ \\
\hline
\end{tabular}

The results are in relation to the total demand of all modeled European countries.

Even though our model yields very rough price calibration and significantly underestimates prices (see Table 4), the development of the price levels in the various pathways still allows us to obtain insights on potential market dynamics. Overall, we observe a tendency towards price increase in the future which can be explained by the reduced domestic supply and higher dependence on imported gas. 
Against this fact, the additional infrastructure projects result in greater availability of gas on the market, and thus in lower prices; Nord Stream 2 has the largest price impact of all pathways due to the assumed low-cost level of Russian supplies. The reduction in the seasonal price spread is mainly explained by the fact that the same suppliers set the prices in summer and winter, as Europe is more dependent on foreign supplies throughout the year.

Table 4: Market Prices

\begin{tabular}{l|c|c|c|c|c} 
& $\begin{array}{c}\text { Market data } \\
\mathbf{2 0 1 3}\end{array}$ & $\begin{array}{c}\text { Baseline } \\
\mathbf{2 0 1 3}\end{array}$ & $\begin{array}{c}\text { As-is } \\
\mathbf{2 0 3 0}\end{array}$ & $\begin{array}{c}\text { Main } \\
\text { Projects }\end{array}$ & $\begin{array}{c}\text { Nord } \\
\text { Stream 2 }\end{array}$ \\
\hline Av. Euro. price [€/mcm] & 0.218 & 0.154 & 0.163 & 0.160 & 0.154 \\
Max price [\% of average] & $116 \%$ & $121 \%$ & $117 \%$ & $115 \%$ & $115 \%$ \\
\hline
\end{tabular}

The results refer to the average of all modeled European countries.

As a summary, one can conclude that the forecasted reduction of domestic natural gas production in Europe implies a diversification of the supply sources. The role of Russia will remain central, but in addition to LNG, the projected pipeline projects in Southern-Eastern Europe might help Europe on its ways towards a higher diversification of supply sources. Overall, the gas infrastructure seems to be sufficient to satisfy Europe's gas needs under average market conditions even without further additions. We do not observe significant price differences within Europe beyond transport costs differentials.

\section{Evaluation of Supply Security}

A key feature of the European gas market today and in the future is its dependency on Russian imports. Whether this dependency represents a threat to the security of gas supply depends on the (im)possibility to compensate a shortage of Russian supplies by other imports. To provide an assessment of this threat, we extend our model with a shock scenario structure: we induce a complete shutdown of the Russian-Ukrainian pipeline, one of the most prominent import routes for Russian gas. The timing of the crisis is chosen to represent a worst-case scenario, so that the transit is disrupted during the four winter months (December to March). To grasp and measure European market's shortterm resilience, we use the average market conditions (as presented in Section 4) as reference by fixing the demand in the crisis conditions to this 'normal' market demand; in other words, we assume a totally inflexible demand during the crisis simulation. This transfers the model into a cost minimization version ( $D_{\text {nit }}$ becomes a parameter). To ensure a feasible model solution even in cases when supply is insufficient, we introduce a 'lost load' variable with prohibitive costs that allows us to identify and locate supply shortages in Europe.

In addition, we countervail the perfect foresight assumption that is necessarily part of an optimization model by fixing all variables of the time periods before the crisis to their respective values of the normal market case. The formulation therefore translates into an unforeseen market shock in which consumers must consume their pre-defined quantity of gas, since they have no alternative for short term switching or other demand reduction measures. To cope with the shortage of gas supply, the 
model can resort to alternative imports and transport routes to ensure stable gas supply if they are available. This fixed demand assumption is likely to overestimate the effect of a supply shock as in reality, one might expect consumer to adapt their consumption to the crisis, at least partially.

In the next section, we will first present the basic results of a supply interruption under different market conditions. Subsequently, we will assess the impact of specific policy approaches to improve supply security.

\subsection{Impact of a Russian Supply Disruption}

In order to obtain insights on the impact of different market conditions and infrastructure projects on the supply security level in Europe, we apply the aforementioned scenario of disruption to our three market pathways and to the base case calibrated model (Baseline 2013).

Baseline 2013 represents the supply disruption under current market conditions. Due to the crucial importance of the Ukrainian route, an interruption of the Russian supply has far reaching consequences for the whole of Europe. Several countries strongly reliant on the Ukrainian transit endure lost load due to insufficient gas supply, among others Ukraine, Bulgaria, Croatia, Italy, Greece or Turkey (Table 5). Roughly 13\% of the European demand during the four crisis months cannot be satisfied. However, also Russia's yearly output is significantly reduced (by 20\%) owing to the lack of available alternative export routes. Hence, one observes a bilateral dependency between Russia and Europe.

With the forecasted levels of production and consumption in the As-is 2030 case, Europe seems less vulnerable to supply disruptions (Table 5). The overall lost load amounts to $9 \%$, which represents a reduction of $-28 \%$ in terms of missing supply compared to the Baseline 2013. At a first glance, this might seem counterintuitive as both European and worldwide gas demand are increasing and import infrastructure stays constant. The As-is 2030 scenario does, nonetheless, introduce large global production capacity extensions, notably for Middle-Eastern countries. These growing LNG import potentials provide Europe with additional flexibility, which represents an essential asset in overcoming such a crisis. Europe is able to import 16 bcm of additional LNG, whereas in the Baseline 2013 almost no supplementary LNG import was possible as the global production capacities were already fully utilized.

The projected infrastructure investments of the Main Projects case result in growing availability of import alternatives to replace the missing Russian gas. Thereby, the overall level of lost load is further reduced (Table 5). The two main beneficiaries of the new infrastructures are Turkey and Greece, who directly profit from the SGC and no longer suffer missing supply. Thanks to the SGC, Italy benefits from increasing export via Greece. In addition, newly implemented LNG import capacities help Croatia and Sweden to improve their supply situation.

The extension of the Nord Stream generates growing Russian exports towards Germany, that supplies part of the missing gas from Ukraine by re-exporting to Poland, Czech Republic and Austria. As a 
result, the pipeline significantly impacts the European security of supply. Ukraine and Romania are the sole countries enduring supply disruption (Table 5). ${ }^{9}$

Table 5: Lost Load in the different market scenarios during crisis

\begin{tabular}{l|c|c|c|c} 
& $\begin{array}{c}\text { Baseline } \\
\mathbf{2 0 1 3}\end{array}$ & $\begin{array}{c}\text { As-is } \\
\mathbf{2 0 3 0}\end{array}$ & $\begin{array}{c}\text { Main } \\
\text { Projects }\end{array}$ & $\begin{array}{c}\text { Nord Stream } \\
\mathbf{2}\end{array}$ \\
\hline Bulgaria & $54 \%$ & $11 \%$ & & \\
Croatia & $65 \%$ & $58 \%$ & $15 \%$ & \\
Greece & $78 \%$ & $21 \%$ & & \\
Italy & $19 \%$ & $8 \%$ & $9 \%$ & $22 \%$ \\
Romania & & & & \\
Slovakia & $69 \%$ & $44 \%$ & & \\
Slovenia & $38 \%$ & $100 \%$ & & \\
Sweden & & $38 \%$ & $7 \%$ & $60 \%$ \\
Turkey & $24 \%$ & $13 \%$ & & $6 \%$ \\
Ukraine & $66 \%$ & $62 \%$ & $59 \%$ & \\
\hline Average Europe & $13 \%$ & $9 \%$ & $7 \%$ & \\
\hline
\end{tabular}

The results are given as percentage of the respective demand during the four crisis months. Countries not listed have no lost load.

Examining the change in flow patterns during the crisis (Figure 2), it becomes visible that the interruption of the Russian-Ukraine pipeline tends to lead to shortages along two main routes. The first one runs though Ukraine-Slovakia-Austria-Czech Republic to Italy; the second from UkraineRomania-Bulgaria to Greece and Turkey. To cope with the missing gas, several alternatives are exploited.

In all cases, one notices 'reverse' flows patterns (gas flowing from Western towards Eastern Europe). The main source for these flows is increasing Norwegian exports channeled through Germany. In some cases, additional supply from Northern Africa can be obtained, either towards Italy ${ }^{10}$ or as LNG exports to Spain. In Main Projects and Nord Stream 2, new infrastructures are used to import additional Russian gas via Turkey that is re-directed towards West. This is especially helpful for the Balkan countries which have sparse alternatives of supply.

Throughout the scenarios, two general trends can be observed. First, the increase in the availability of production capacity forecasted by the IEA, notably in the Middle-East, results in enhanced gas security in Europe. Second, infrastructure projects further have a strong positive impact on the European short-term SoS. ${ }^{11}$

\footnotetext{
${ }^{9}$ Nord Stream 2 causes higher lost load than Main Projects for Ukraine and Romania due to feedback effects from the pipeline extension. The crisis assessment is based on an uninterrupted market simulation providing the respective load levels. The extension of the Nord Stream connection reduces the natural gas flow over the Russian-Ukrainian route, increases the availability of transport capacity, and thus yields shrinking prices for several Eastern European countries under normal market conditions. Furthermore, Romania and Ukraine display a less pronounced price spread between winter and summer, which reduces their incentive to store gas. The overall higher demand level and reduced storage levels following the introduction of the Nord Stream 2, mean they are more prone to supply disruptions. Therefore, there exists a counterproductive effect of an increased supply for the energy security of some regions.

${ }^{10}$ Nonetheless, as the shock occurs at the peak time of gas consumption in Europe, spare production capacity is a scarce resource. The growing pipeline flows from Algeria and Libya towards Italy in the Baseline 2013 case are only made possible thanks to a reduction of their $\mathrm{LNG}$ exports.

${ }^{11}$ The extension of Nord Stream can also create a trade-off for the current transit countries of other Russian pipelines (e.g. Poland), between the loss of transport fees and an enhanced European security of supply.
} 
Figure 2: Flow reallocation during the four crisis months

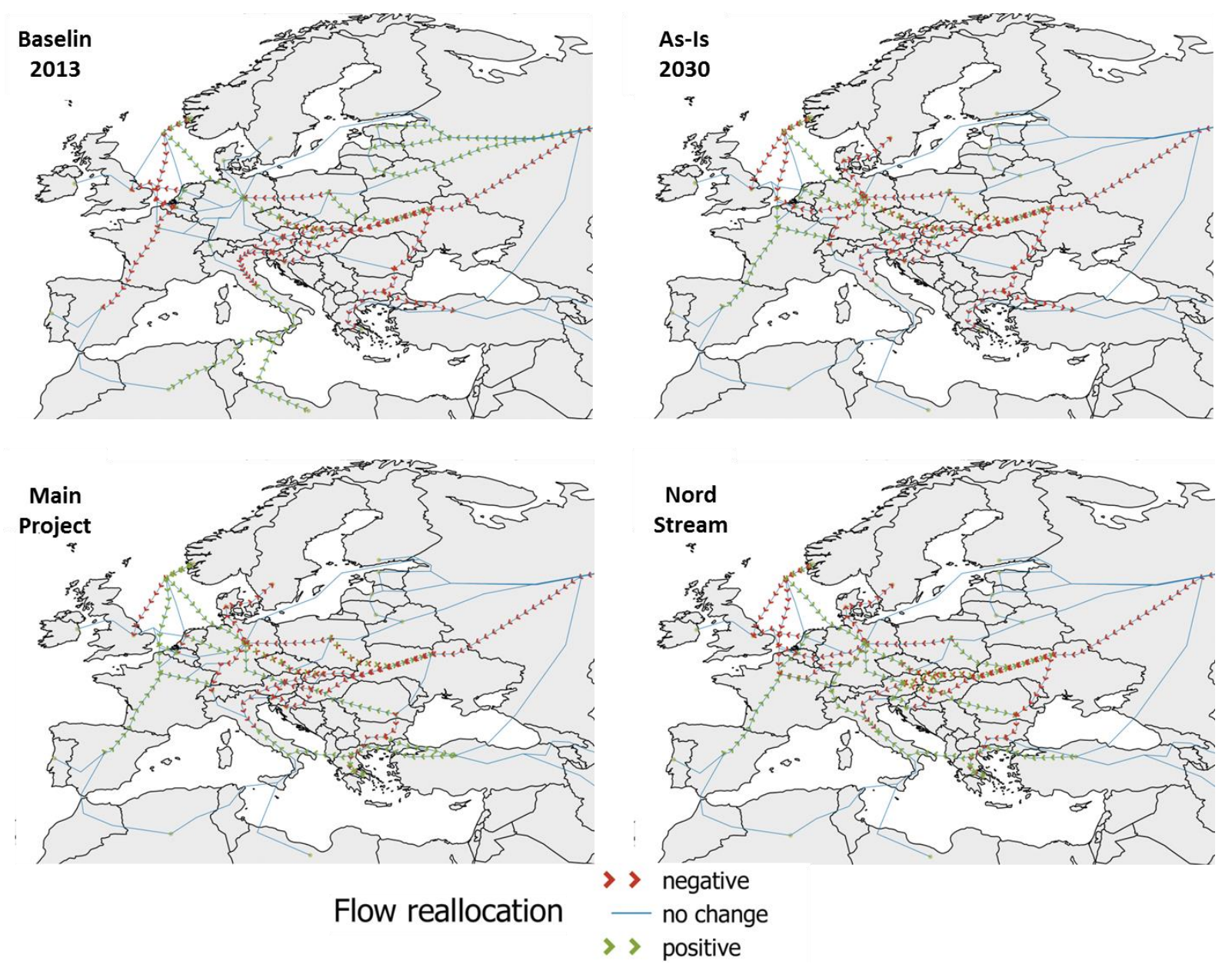

\subsection{Impact of Supply Security Policies}

As shown by the above assessments, the average European market conditions do not show significant supply constraints or extensive congestion problems. However, the overall dependency on Russian gas is seen critical and can be a source of trouble in case of delivery interruptions. The currently discussed extension of the European gas infrastructure might help to weaken, at least to partially counter this threat. On the contrary, Nord Stream 2 is often seen as enlarging the dependency and potentially increasing the threat for East Europe in case of supply disruptions, albeit our results indicate that this is not necessarily the case. Nonetheless, given the fact that the main challenge consists rather in managing specific extreme conditions than in structural problems of the market, one may think about alternative approaches that could provide additional supply security without the need for costly infrastructure investments.

Against this background, we extend our assessment by simulating the impact of specific policies targeting a more secure supply; namely:

1. Strategic Storage: Imposing an obligation to maintain a specific storage level for emergency situations. 
2. European Storage Coordination: As not all countries can rely on own or sufficient storage capacities, coordination among countries during the crisis is key. This policy seeks to tackle this question by assessing the difference between cases where countries can or cannot share their strategic storage with each other.

3. Long-Term Contracts: As a significant share of international gas trade is conducted via bilateral long-term agreements those contracts could in principal entail a supply guarantee priority during emergencies. Based on the exiting long-term contract structure we evaluate the impact if those would include a priority supply for the contract holders.

Following, we present these different policies and simulate their impact using the same model framework as for the Russian supply disruption assessment.

\subsubsection{Impact of Strategic Storage}

Storage is a prominent flexibility provider, both to cover fluctuations of seasonal demand and in case of supply disruptions. Recognizing its importance, several European countries have put in place a strategic storage policy. For instance, Italy imposes a minimum storage level of $4.6 \mathrm{bcm}$ of gas. In Hungary, gas suppliers are required to store $10 \%$ of the total demand. A detailed overview of the national policies can be found in EC (2015).

Our first policy assessment simulates the implementation of a strategic reserve obligation at the European level. We define the obligation as a fixed percentage of each country's storage capacity. The storage obligation must be held throughout the year and can only be used in case of a crisis. If the strategic reserves have been used to overcome a crisis, they must be refilled at the latest five months after the end of the crisis. To evaluate the policy's impact on SoS, we implement the Russian crisis scenario for different level of storage obligation.

Table 6: Impact of the storage obligation policy on Europe (Baseline 2013)

\begin{tabular}{|c|c|c|c|c|c|c|c|}
\hline $\begin{array}{l}\text { Storage } \\
\text { obligation }\end{array}$ & $\begin{array}{c}\text { Avg. } \\
\text { Storage } \\
\text { Level }\end{array}$ & $\begin{array}{c}\text { Withdr. } \\
\text { base } \\
\text { [bcm] }\end{array}$ & $\begin{array}{c}\text { Withdr. } \\
\text { crisis } \\
\text { [bcm] }\end{array}$ & $\begin{array}{l}\text { Lost } \\
\text { Load } \\
{[\text { bcm] }}\end{array}$ & $\begin{array}{c}\text { LL / } \\
\text { Demand }\end{array}$ & $\begin{array}{c}\text { Increase } \\
\text { Cons. } \\
\text { Exp. }\end{array}$ & $\begin{array}{c}\text { Increase } \\
\text { Prod. } \\
\text { Profit }\end{array}$ \\
\hline $0 \%$ & $66 \%$ & 66.4 & 68.2 & 39.4 & $12.90 \%$ & - & - \\
\hline $10 \%$ & $71 \%$ & 64.1 & 76.7 & 29.1 & $9.60 \%$ & $1.3 \%$ & $2.3 \%$ \\
\hline $20 \%$ & $76 \%$ & 60.7 & 86.6 & 16.5 & $5.50 \%$ & $2.9 \%$ & $6.5 \%$ \\
\hline $30 \%$ & $79 \%$ & 54.2 & 85.5 & 11.4 & $3.80 \%$ & $5.8 \%$ & $16.1 \%$ \\
\hline $40 \%$ & $83 \%$ & 47.1 & 85.5 & 7.5 & $2.60 \%$ & $9.2 \%$ & $28.4 \%$ \\
\hline $50 \%$ & $88 \%$ & 41.1 & 83.5 & 4 & $1.40 \%$ & $12.1 \%$ & $37.1 \%$ \\
\hline $60 \%$ & $91 \%$ & 35.6 & 81.9 & 0.5 & $0.20 \%$ & $14.9 \%$ & $47.0 \%$ \\
\hline $70 \%$ & $96 \%$ & 30.8 & 78.9 & & & $17.9 \%$ & $58.0 \%$ \\
\hline $80 \%$ & $98 \%$ & 25.7 & 69.3 & & & $21.2 \%$ & $70.6 \%$ \\
\hline $90 \%$ & $100 \%$ & 14.2 & 58.8 & & & $26.3 \%$ & $89.2 \%$ \\
\hline
\end{tabular}

Strategic storage obligations have two major effects. On the one hand, this policy augments the possibility to recourse to storage gas in case of a crisis. The impact on the European market should, 
thus, be positive. On the other hand, the obligation reduces the available capacity for commercial storage, and might, therefore, hinder seasonal arbitrage. Hence, the direction of the overall impact is unsure.

Using the Baseline 2013 as starting point, Fehler! Verweisquelle konnte nicht gefunden werden. highlights the basic dynamics of the storage obligation: more stringent storage obligations lead to higher level of storage and, thus, to more available alternatives to cope with the missing Russian exports. The stored gas is used for both, national demand and shared with neighboring countries. For storage obligation above $40 \%$, Europe is capable to cope with a four months disruption of Ukrainian transit with only marginal lost load. The crisis is overcome without any supply disruption at levels of mandatory reserves above $70 \%$.

However, this increase in security comes at a price. There exists a crowding out effect which occurs when imposing a more stringent policy: the larger the storage obligation, the smaller the remaining storage capacity available for seasonal arbitrage. This effect is highlighted in the second column of Fehler! Verweisquelle konnte nicht gefunden werden., where one notes the decreasing trend of storage withdrawals during winter season in the base case. The radical formulation of the policy, in which storage operators are forced to maintain a minimum level throughout the year that can only be released in a crisis situation, leads to significant limitation of the storage usage. ${ }^{12}$

In addition to reduced withdrawals in winter, the strategic storage needs to be filled with an additional amount of gas purchased on the market beforehand. We assume a constant minimum storage level throughout the year. Therefore, the storage is only filled once the policy is introduced or after a crisis led to refill the strategic storage. ${ }^{13}$ A more limited storage requirement - i.e. only during the winter months - could lead to a different operation pattern causing operators to buy more gas on the market during the filling season to fulfil their winter obligation leading to regularly reoccurring price alterations. Both effects lead to higher average gas prices on the European market in the non-crisis conditions. Increasing prices can be seen before the winter season (need to fulfil the winter storage requirement) and will be seen in the peak winter time (the diminishing withdrawals must be compensated elsewhere). These price increases lead to higher expenses for consumers and higher profits for producers (see last two columns from Fehler! Verweisquelle konnte nicht gefunden werden.).

Overall, the effect of strategic reserve policy can be summed up as follow: on the one hand, it brings along substantial benefits in terms of energy security. The strategic storage is used as a buffer, which helps to cope with unforeseen circumstances and severe crises. On the other hand, however, the policy induces certain costs. First, the cost of filling up the strategic storage must be paid. As this would represent a regulatory measure, the associated costs are likely to be passed on to consumers. Second,

\footnotetext{
${ }^{12}$ This negative effect could be reduced if the strategic storage is allowed to be gradually released over the winter time if no crisis occurs.

${ }^{13}$ Within the model we include several months of lead time, starting in spring of the year before to allow the strategic storage to be filled.
} 
the strategic reserve restrains the commercial usage of storage, thus foregoing potential seasonal arbitrage. Third, stringent filling obligation lead to market-wide reactions: growing overall demand for gas due to the higher storage needs, higher prices, and larger price spreads on the market. This negatively impacts the consumers. The question is then on the value attached to the supply security. Looking at Fehler! Verweisquelle konnte nicht gefunden werden., one notices that a level of storage obligation of $20 \%$ already halves the missing supply, while causing an increase of $3 \%$ of consumer expenses. Depending on the valuation of supply security, this might be considered an acceptable compromise.

Turning to the three infrastructure pathways-As-is 2030, Main Projects, and Nord Stream 2-the basic insights remain valid. The storage obligation leads in all cases to enhanced security of supply in terms of a reduction of the lost load (Table 7). Each infrastructure setting yields a more flexible gas supply, which translates into smaller impact of the pipeline shutdown. Nonetheless, the strategic storage policy helps to overcome the supply disruptions in a similar way as it did for the Baseline 2013.

Table 7: Impact of storage obligation in 2030 cases on Europe

\begin{tabular}{|c|c|c|c|c|c|c|}
\hline \multirow[b]{2}{*}{$\begin{array}{l}\text { Storage } \\
\text { obligation }\end{array}$} & \multicolumn{3}{|c|}{ Lost Load } & \multicolumn{3}{|c|}{ Increase in Consumer Expenses } \\
\hline & As-is 2030 & $\begin{array}{c}\text { Main } \\
\text { Projects }\end{array}$ & $\begin{array}{c}\text { Nord } \\
\text { Stream } 2\end{array}$ & As-is 2030 & $\begin{array}{c}\text { Main } \\
\text { Projects }\end{array}$ & $\begin{array}{c}\text { Nord } \\
\text { Stream } 2\end{array}$ \\
\hline $0 \%$ & $9 \%$ & $7 \%$ & $6 \%$ & $0 \%$ & $0 \%$ & $0 \%$ \\
\hline $10 \%$ & $6 \%$ & $4 \%$ & $5 \%$ & $1 \%$ & $1 \%$ & $0 \%$ \\
\hline $20 \%$ & $5 \%$ & $3 \%$ & $4 \%$ & $2 \%$ & $2 \%$ & $1 \%$ \\
\hline $30 \%$ & $4 \%$ & $3 \%$ & $3 \%$ & $4 \%$ & $3 \%$ & $1 \%$ \\
\hline $40 \%$ & $3 \%$ & $2 \%$ & $2 \%$ & $6 \%$ & $5 \%$ & $2 \%$ \\
\hline $50 \%$ & $1 \%$ & $1 \%$ & $1 \%$ & $8 \%$ & $8 \%$ & $3 \%$ \\
\hline $60 \%$ & & & & $9 \%$ & $10 \%$ & $3 \%$ \\
\hline $70 \%$ & & & & $11 \%$ & $12 \%$ & $6 \%$ \\
\hline $80 \%$ & & & & $14 \%$ & $14 \%$ & $9 \%$ \\
\hline $90 \%$ & & 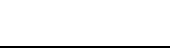 & 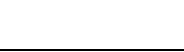 & $17 \%$ & $16 \%$ & $11 \%$ \\
\hline
\end{tabular}

One of the main drawbacks of the strategic reserve policy is that it prevents the flexible use of storage and, therefore, leads to higher prices preventing inter-seasonal arbitrage. As the infrastructure scenarios result in additional flexibility of supply on the European market, this effect is less pronounced than in the Baseline 2013 case (Fehler! Verweisquelle konnte nicht gefunden werden. and Table 7). However, since the level of lost load is also lower than in the Main Projects and Nord Stream 2 cases, the question remains open whether the additional benefit in terms of better supply during crisis conditions is worth the additional cost.

Our results also lead to the additional question of whether a storage policy is a more cost-efficient solution than investments in infrastructure to address Europe's supply security concerns. The overall benefit of the two infrastructure cases is a decrease in the lost load level of about 2 to 3 percentage points. The same improvement can be obtained by imposing a 10 or $20 \%$ storage obligation which 
leads to about 1 to $2 \%$ higher consumer prices (Table 7 ). ${ }^{14}$ Naturally, further factors play into the investment decision, yet from a pure supply security perspective, investment in new infrastructure may not represent the most cost-efficient solution.

As a final remark, one must note that our results depend on the underlying assumptions. In the Appendix, we provide a set of different sensitivities addressing the way how we model the costs of storage and how we define the strategic storage rules. The assumptions do change the obtained numerical values but do not fundamentally alter the benefits of the policy or the general conclusions. As increases in strategic storage obligations always lead to an increase in supply security the question is, how stringent the policy should be formulated, and hence, how large the disadvantages of the policy on the consumers' wallets will be. A more flexible implementation (i.e. gradually freeing up strategic storage over winter months) is likely to lead to smaller negative impacts.

\subsubsection{Impact of European Coordination}

In the previous analysis, we assumed that all European countries jointly participate in the policy and exchange their strategic gas reserve in an optimal way for the European welfare. Yet, one notes strong divergence among storage capacities of European countries (Table 8). While Austria can approximately cover its entire annual consumption with a full storage, Germany, France or Italy have capacity for around one quarter of their annual demand in storage. And countries like Greece and Switzerland have no domestic storage and would depend on the provision by neighboring countries. In a crisis case, countries with limited storage capacity rapidly exhaust their entire stored gas and subsequently have to rely on additional supply by their neighbors. Hence, cooperation between the European players seems a key feature of a strategic storage policy.

Table 8: Storage capacity as percentage of annual (2013) consumption for selected countries

\begin{tabular}{ll|ll|ll}
\hline AUT & $97 \%$ & ESP & $14 \%$ & HUN & $68 \%$ \\
BEL & $4 \%$ & FRA & $27 \%$ & ITA & $24 \%$ \\
CZE & $41 \%$ & GBR & $6 \%$ & NLD & $28 \%$ \\
DNK & $26 \%$ & GER & $28 \%$ & UKR & $65 \%$ \\
\hline
\end{tabular}

To assess the impact of this cooperation, we compare two different cases: a cooperative and a noncooperative one. In the latter, gas in strategic storage may only be used to cover a country's own needs, whereas in the former, the strategic reserve might be shared with neighbors.

To implement this approach in our model, we need to limit the usage of gas to a country's own lost load in the non-cooperative case even if there is more gas in the storage than there is demand shortage. To achieve such a restriction, we use an additional model run for reference that entirely forbids the use of strategic storage reserves. This allows us to identify the amount of lost load a country has to cope

\footnotetext{
${ }^{14}$ However, a direct comparison of those price increases with the needed investment costs (i.e. for the Southern Gas Corridor a total investment volume of US\$40 billion is assumed, https://www.tap-ag.com/the-pipeline/the-big-picture/southern-gascorridor, for Nord Stream 2 cost in a similar range like Nord Stream 1 of $€ 40$ billion can be expected, https://www.nordstream.com/download/file/documents/pdf/en/2013/11/nord-stream-by-the-numbers_177_20131128.pdf) is complicated as non supply security related aspects of the investments need to be taken into account.
} 
with on its own. This value can then be set in relation to a country's strategic storage reserves. ${ }^{15}$ If a country's strategic reserve is short, it has to rely on increased imports or suffers lost load. Contrary, if a country has surplus storage capacity, it will use its storage to compensate the demand shortage but not provide surplus stored gas for neighboring countries. It is to be noted, that for all runs, the commercial storage (i.e. the non-strategic storage) can be freely used and shared.

The general importance of cooperation for an efficient crisis management is highlighted in Figure 3 by comparing the welfare effects of the different settings for the Baseline 2013 case. One notices the large differences between the two crisis cases. The non-cooperation can cause a reduction in total welfare of up to $28 \%$. Since strategic reserves cannot be shared, their potential is not fully used. Several regions suffer lost load, although their neighboring countries might have remaining stored gas.

Figure 3: Impact of strategic storage and cooperation on system welfare (billions USD $_{2013}$ )

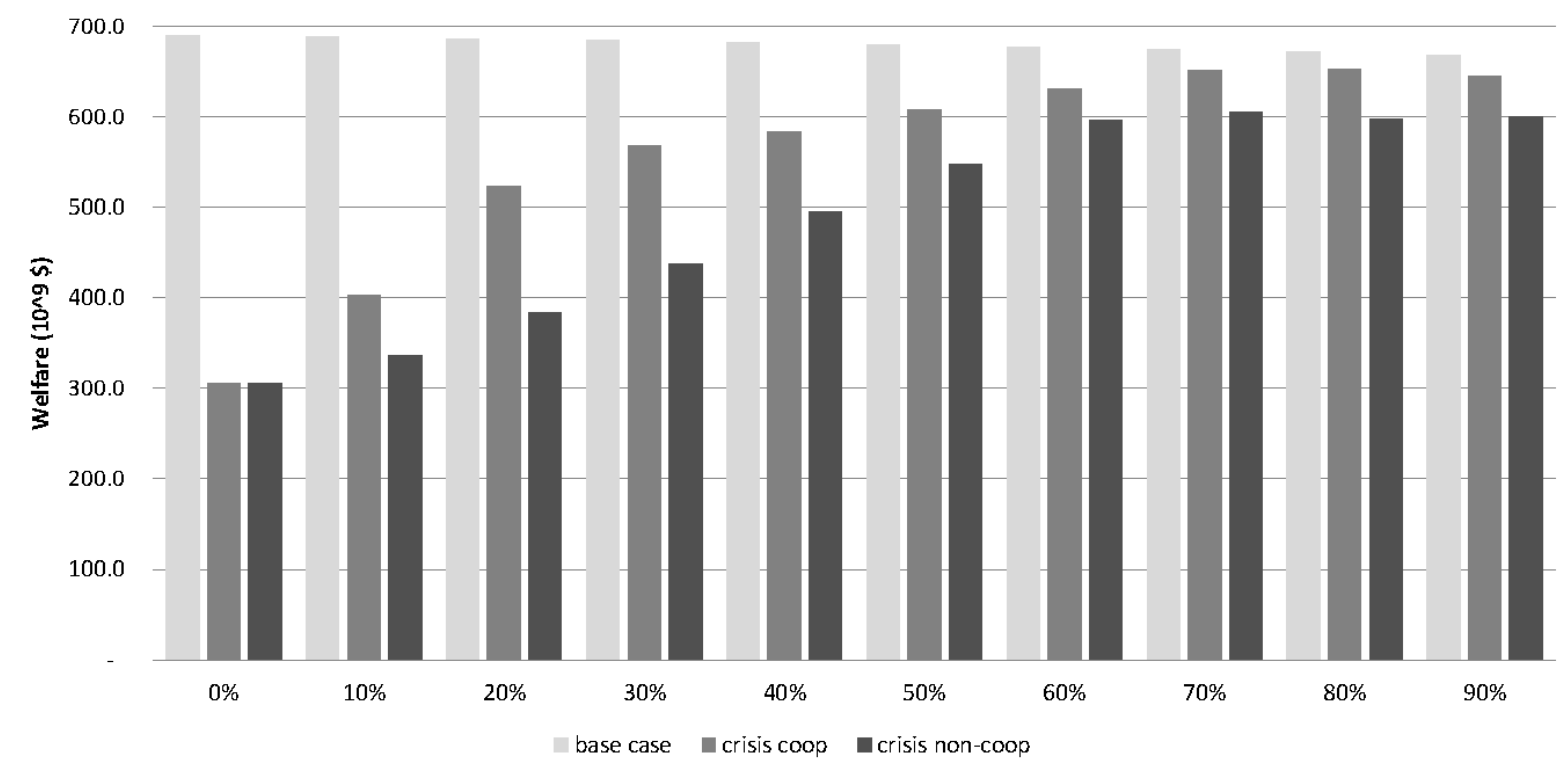

Total system welfare for Europe. The absolute value of the crisis case is strongly impacted by the assumed costs of lost load $(10$ '000 \$/bcm)

The differences between the two cases first increase until the $20 \%$ storage level (peaking at a difference of 28\%), shrink afterwards until $60 \%$ and $70 \%$ (going as low as 5\% difference), and increase again for the $80 \%$ and $90 \%$ case (to ca. $10 \%$ difference). To explain this pattern, one must consider the trade-off caused by the policy. A larger strategic reserve leads to enhanced availability of gas to cope with the crisis, while it also reduces the quantity of commercially stored gas. In the context of this scenario analysis, this trade-off is even more important, as a distinction between commercial and strategic storage is made. Hence, the impact of this trade-off is different in the cooperative and the

\footnotetext{
${ }^{15}$ Technically the approach is implemented as a three-step model: First, the base case market results are obtained with the respective storage obligation in place. Second, a crisis run is carried out without the possibility to use the strategically stored gas. This run defines the levels of lost load for each country. This lost load is then compared to the strategic storage volume and a netted demand position is defined (i.e. if the storage volume is bigger than the lost load, the demand is fully reduced by the lost load value; if the volume is smaller than the lost load the demand is only reduced by the storage volume) as well as the remaining strategic storage volume is identified. In a third run, the crisis case with adjusted demand level is simulated. Depending on the case either with free exchange of the remaining strategic storage volume (cooperation case) or exclusion of the remaining volume (non-cooperation case).
} 
non-cooperative settings. In the cooperative case, only the increased availability of stored gas is relevant, since both, strategic and commercial storage can be freely used and shared. On the contrary in the non-cooperative case, only commercial reserves might be distributed among neighbors.

Therefore, increasing strategic storage has a twofold effect on the supply security in the noncooperative case; positive on the one hand (more gas in storage for one's own needs) and negative on the other hand (less commercial storage to be shared). The direction of the overall impact depends notably on the storage occupancy before the policy implementation. Provided a country has already a rather filled storage, the strategic storage obligation will mainly result in a crowding out of the private reserves. Hence, a more stringent reserve obligation could make the neighbors worse off. On the contrary, if the storage of a country is fairly empty, the policy will increase its total reserve level. This is in turn directly beneficial for the country's supply security. Although the strategic reserves cannot be shared in the "non-cooperative" case, it might still have a positive indirect effect on the neighbors, as it reduces the demand for gas in case of crisis.

Figure 4: Total commercial storage availability in November by storage obligation

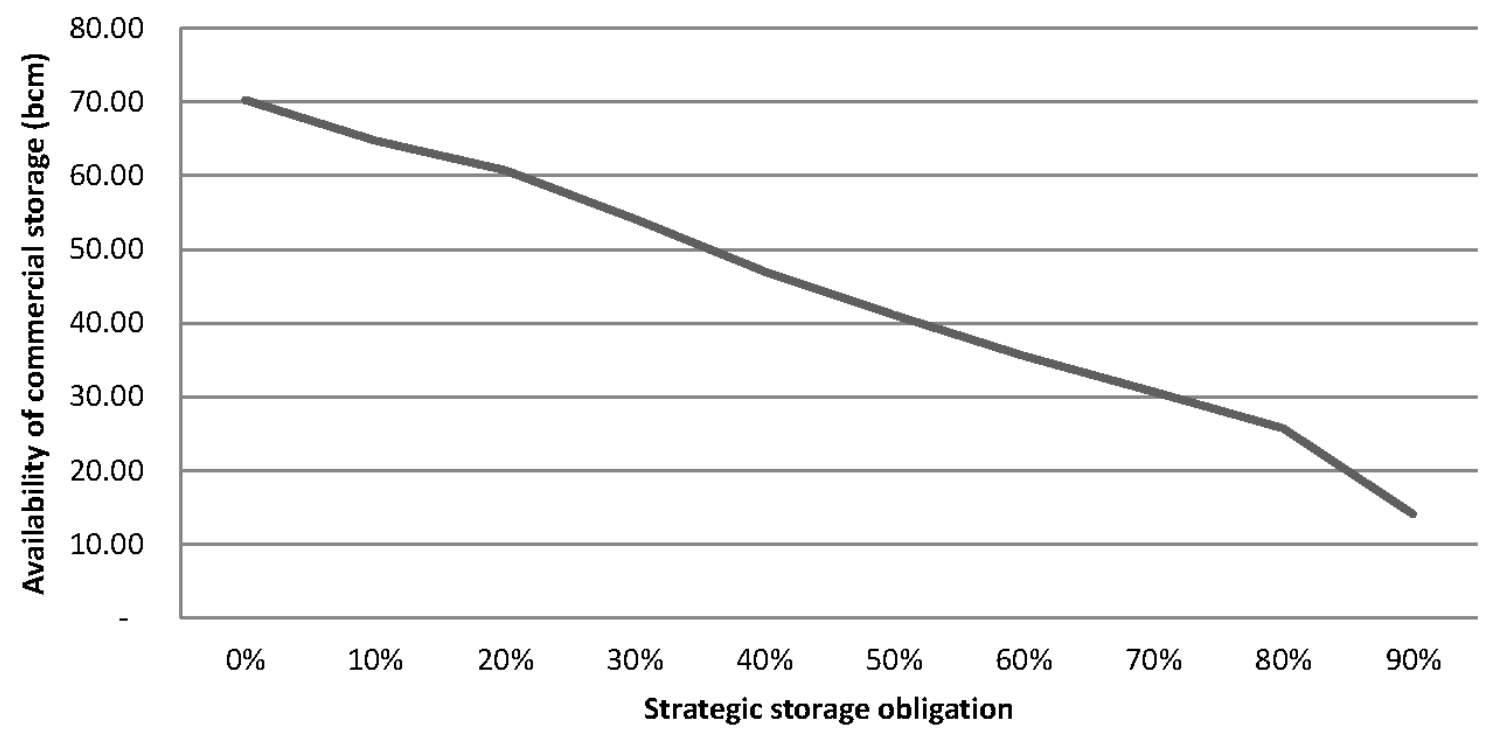

To visualize this interaction Figure 4 shows the impact of the storage obligation on the free available storage volume in Europe. The crowding out effect starts rather slowly, thus the positive impact of the policy dominates. Each increase of the storage requirement yields a larger pool of reserves to be shared in the cooperative case; however, in the non-cooperative one, this pool is diminishing. Hence, the difference between the two cases is growing. From $30 \%$ onwards we observe a decreasing growth in the total pool of storage (i.e. a reduced growth in the overall benefits of the policy). This leads to the decrease in the difference between the two cases. For high storage obligations, the available commercial storage is plunging (for instance because Germany reaches its storage capacity). Hence, the sharing of the reserves is drastically reduced. Each country must then be self-sufficient, and the nation with insufficient storage capacities might endure lost load again. This explains why the difference is growing for very high obligations. 
Lastly, looking into country specific effect we can identify which countries benefit most from a cooperative policy (Table 9). Since Greece does not hold gas storage capacity, it suffers severe supply disruption in the non-cooperative set-up; whereas in the cooperative case, the country can fully satisfy its demand at high level of storage obligation. The same observation is valid for Croatia or Italy, who both possess significant storage capacities, yet covering only a limited part of their yearly demand (roughly $20 \%$ in both cases). For a country with a relatively large storage like Ukraine, one notices that the impact of the cooperation is more restricted, yet still positive. Other countries with little storage capacities, like Switzerland, are less impacted as they rely less on gas from Russia.

Table 9: Lost load over demand during the crisis for selected countries in the non-cooperative and the cooperative cases

\begin{tabular}{|c|c|c|c|c|c|c|c|c|}
\hline \multirow{2}{*}{$\begin{array}{l}\text { Storage } \\
\text { obligation }\end{array}$} & \multicolumn{4}{|c|}{ Cooperative Case } & \multicolumn{4}{|c|}{ Non-Cooperative Case } \\
\hline & CRO & GRC & ITA & UKR & CRO & GRC & ITA & UKR \\
\hline $0 \%$ & $65 \%$ & $78 \%$ & $19 \%$ & $66 \%$ & $65 \%$ & $78 \%$ & $19 \%$ & $66 \%$ \\
\hline $10 \%$ & & $78 \%$ & $9 \%$ & $68 \%$ & $66 \%$ & $78 \%$ & $19 \%$ & $68 \%$ \\
\hline $20 \%$ & & $35 \%$ & & $43 \%$ & $64 \%$ & $78 \%$ & $17 \%$ & $53 \%$ \\
\hline $30 \%$ & & $17 \%$ & & $34 \%$ & $67 \%$ & $60 \%$ & $14 \%$ & $47 \%$ \\
\hline $40 \%$ & & $33 \%$ & & $21 \%$ & $70 \%$ & $63 \%$ & $6 \%$ & $33 \%$ \\
\hline $50 \%$ & & $48 \%$ & & $23 \%$ & $74 \%$ & $68 \%$ & $3 \%$ & $17 \%$ \\
\hline $60 \%$ & & $26 \%$ & & & $77 \%$ & $50 \%$ & $1 \%$ & $7 \%$ \\
\hline $70 \%$ & & & & & $82 \%$ & $50 \%$ & & \\
\hline $80 \%$ & & & & & $86 \%$ & $50 \%$ & & \\
\hline $90 \%$ & & & & & $91 \%$ & $36 \%$ & & \\
\hline
\end{tabular}

Summarizing the findings, we can conclude that European coordination is a highly valuable aspect of a security of supply policy. Without proper exchange and coordination on measurers during supply shortages the needed countermeasures need to be scaled up significantly to achieve a similar effect, with some countries not being able to achieve a comparable effect at all.

\subsubsection{Impact of Long-term Contracts}

In addition to infrastructure investments and storage operation, bilateral supply contracts can further represent a form of supply insurance in case of an overall market shortage. As stated in Section 3.1, we use the database of Neumann et al. (2015) of long-term contracts in Europe. These contracts were historically prominent for the European gas market covering the vast majority of gas imports in many countries. Nowadays, their relevance is challenged by the rising importance of sport markets. Despite these changes, they remain a significant part of gas importers' portfolio, especially when speaking about the security of supply. One can consider long-term contract as a more 'secure' source of supply as it ensures the quantities of gas delivered as long as parties stick with the terms of contract.

Given this reasoning and the fact that long-term contracts still cover a large share of European consumption, we investigate the impact of these contracts on the European security of supply. To that extent, we compare two different cases. In the first one, countries do not have to stick with contracts during a crisis (disruption of the Russian-Ukrainian pipeline). Hence, they do not face any 
consequences if they fail to deliver the promised gas. On the contrary, in the second one, exporters have to stick with the contract and pay a financial penalty in case of failing to deliver. To simulate this, we introduce a differentiated cost of lost load for the share of demand covered by long-term contracts. Defaulting on these consumers will thus be more expensive than on other ones.

Table 10 displays the resulting average lost load in percent of demand for the European countries which must endure missing supply during the crisis. Comparing the case with and without penalty, one notes the clear impact of the long-term contracts on security of supply. The introduced financial incentive dissuades exports to default on their long-term commitments. Thereby, the countries which had a high share of contracts are better off than others. Greece, Italy, Portugal, and Turkey are all freed from their lost load problems, while even the Ukraine can reduce its missing gas share.

On the other side, countries which do not possess long-term contracts are penalized by the new situation. From a system point-of-view, it is now optimal for exporters to default on these countries, rather than on those holding long-term contracts. Thus, the missing supply problem is shifted toward Eastern European countries like Bulgaria, Croatia, Slovakia or Slovenia. Even Romania suffers lostload despite a share of $16 \%$ of long-term contract. On the Western end, Great-Britain and Ireland also both see enhanced problems supply security which is mostly due to a reallocation of Norwegian gas and LNG for countries with long-term contracts. Some countries are, in turn, unaffected by the policy, as they do not face shortages in supply in any of the cases. This is for example the case of Switzerland.

Table 10: Impact of long-term contracts on lost load

\begin{tabular}{|c|c|c|c|}
\hline Country & $\begin{array}{c}\text { Long-term contracts } \\
\text { share }\end{array}$ & $\begin{array}{c}\text { Lost Load } \\
\text { without contracts }\end{array}$ & $\begin{array}{c}\text { Lost } \text { Load } \\
\text { with contracts }\end{array}$ \\
\hline Bulgaria & & $40 \%$ & $100 \%$ \\
\hline Croatia & & $42 \%$ & $60 \%$ \\
\hline Great Britain & & & $13 \%$ \\
\hline Greece & $63 \%$ & $9 \%$ & \\
\hline Hungary & & & $5 \%$ \\
\hline Ireland & & & $87 \%$ \\
\hline Italy & $62 \%$ & $14 \%$ & \\
\hline Portugal & $58 \%$ & $37 \%$ & \\
\hline Romania & $16 \%$ & & $69 \%$ \\
\hline Slovakia & & & $100 \%$ \\
\hline Slovenia & & $23 \%$ & $100 \%$ \\
\hline Spain & $27 \%$ & $9 \%$ & $5 \%$ \\
\hline Sweden & & & $49 \%$ \\
\hline Turkey & $54 \%$ & $20 \%$ & \\
\hline Ukraine & $39 \%$ & $62 \%$ & $52 \%$ \\
\hline
\end{tabular}

Summing up, one notices that a financial penalty for breach of contract, discouraging exporters to default on their long-term contract, might be a powerful tool to enhance countries' security of supply. The question of whether the parties in a long-term contract will accept such a clause and of whether, in the absence of such a penalty, the exporters will favor its long-term clients over others remains to be answered. 


\section{Conclusion}

The recurring political tensions between Moscow and Kiev, the debate about Nord Stream 2, and the ongoing liberalization process of the European gas market raised concerns about energy security. Numerous research efforts have been devoted to tackle this issue, yielding heterogeneous insights. In this context, the present study draws on existing literature on the modeling of energy to formulate an optimization model of the European natural gas market to provide an assessment of the supply security under different system developments and policy settings. The results indicate a general sufficient European gas infrastructure under normal market conditions. The existing pipeline and LNG infrastructure in Europe and the expected increase in global gas production are sufficient to compensate the reduction in indigenous European gas extraction. However, the strong dependency on Russia leads to subsequent threats on supply security. Based on these general system characteristics the different supply security assessments allow three main conclusions.

First, the projected extension in terms of LNG terminals and the Southern Gas corridor might help to improve the security of supply, yet are not sufficient to completely eliminate the threat of demand curtailments in case of Russian-Ukrainian transit disruptions. North Stream 2, on the other hand, reduces the importance of the Ukrainian route, on the expense of increasing the reliance on Russian gas. Equally important to Europe's infrastructure is the capability of the global gas market to provide flexible gas that can be reallocated towards Europe. The expected increase in global production capacities is likely to improve this situation. However, if the market cannot react, additional import capacity may not provide any benefit for critical situation. In this context, the role of reverse flows is even more important, as they allow gas imports to be reallocated and to reach those regions with supply shortages.

First, the projected extension in terms of LNG terminals and the Southern Gas corridor might help to improve the security of supply, yet are not sufficient to completely eliminate the threat of demand curtailments in case of Russian-Ukrainian transit disruptions. North Stream 2, on the other hand, reduces the importance of the Ukrainian route, on the expense of increasing the reliance on Russian gas. Equally important to Europe's infrastructure is the capability of the global gas market to provide flexible gas that can be reallocated towards Europe. The expected increase in global production capacities is likely to improve this situation. However, if the market cannot react, additional import capacity may not provide any benefit for critical situation. In this context, the role of reverse flows is even more important, as they allow gas imports to be reallocated and to reach those regions with supply shortages.

Second, policies tackling the management of storage seem a cost-efficient method to meliorate supply security. A relatively modest amount of strategic storage of $20 \%$ to $30 \%$ already allows to cover the majority of demand curtailment for a four-month Russian supply shortage. Assuming further shortterm flexibility options that cannot be represented with the model approach, like demand management and bi-fuel consumers, this is likely to suffice for most of the crisis situations. At the same time the costs of this policy are rather modest as the reduced capability for seasonal arbitrage is not yet 
significantly reduced at this obligation level. Furthermore, gradually freeing up the strategic storage over the winter months will further reduce the negative market impacts.

Third, to achieve an efficient crisis management, coordination across European countries is essential. Purely national approaches will lead to suboptimal decisions and require a higher effort to achieve similar outcomes as a coordinated approach. Consequently, if introducing security storage obligations, one must set clear rules on their operation during a crisis situation. As the storage capacity in relation to the demand varies greatly across European countries, it seems crucial to ensure collaboration among neighbors and coordination in crisis management. The assessment of the role of long-term contracts points in a similar direction. While they provide higher supply security for the signing party, they can negatively impact other European countries. An optimal European policy approach therefore is likely to trigger trade-offs and may potentially require compensations to incentivize all countries to participate

Given the main findings of the paper we conclude that the overall assessment for Europe's supply situation is relatively positive, as the region already possesses most of the needed structures to address longer shortages.

These various insights on the European security of supply pave the way for further research. Albeit a prominent concept, energy security is difficult to measure. Through shock scenarios, as in the present work, one obtains an appreciation of the short-term resilience. One could then combine various shock scenarios into a single indicator, measuring the short-term energy security. This metrics should then be compared to other indicators of supply security, for instance related to long-term aspects of the concept, to obtain a truly global assessment of the security of supply. A first conceptualization of such an indicator is provided in Abrell et al. (2019). 


\section{Bibliography}

Abrell, J. and Weigt, H. (2012). Combining energy networks. Networks and Spatial Economics, 12(3):377-401.

Abrell, J. and Weigt, H. (2016a): Investments in a Combined Energy Network Model: Substitution between Natural Gas and Electricity? The Energy Journal, 37(4):63-86.

Abrell, J. and Weigt, H. (2016b): The Short and Long Term Impact of Europe's Natural Gas Market on Electricity Markets until 2050. The Energy Journal, 37(SI3):125-146.

Abrell, J., Chavaz, L., and Weigt, H. (2019): Assessing supply security - A compound indicator. SCCER CREST Working Paper.

Austvik, O. G. (2004). Strategic gas reserves and EU security-of-supply. Energy Studies Review, 12(2):192-207.

Boots, M. G., Rijkers, F. A., and Hobbs, B. F. (2004). Trading in the down- stream European gas market: a successive oligopoly approach. The Energy Journal, 25(3):73-102.

Cayrade, P. (2004). Investments in gas pipelines and liquefied natural gas infrastructure. What is the impact on the security of supply? FEEM Working Paper.

Chaton, C., Creti, A., and Villeneuve, B. (2009). Storage and security of supply in the medium run. Resource and Energy Economics, 31(1):24-38.

Correlje, A. and Van der Linde, C. (2006). Energy supply security and geopolitics: A European perspective. Energy Policy, 34(5):532-543.

Costantini, V., Gracceva, F., Markandya, A., and Vicini, G. (2007). Security of energy supply: comparing scenarios from a European perspective. Energy Policy, 35(1):210-226.

Dieckhoöner, C., Lochner, S., and Lindenberger, D. (2013). European natural gas infrastructure: the impact of market developments on gas flows and physical market integration. Applied Energy, 102:994-1003.

Egging, R., Gabriel, S. A., Holz, F., and Zhuang, J. (2008). A complementarity model for the European natural gas market. Energy Policy, 36(7):2385-2414.

Egging, R., Holz, F., and Gabriel, S. A. (2010). The World Gas Model: A multi-period mixed complementarity model for the global natural gas market. Energy, 35(10):4016-4029.

Eikon (2015). Thomson Reuters Eikon - Natural Gas Market Data.

Eikon (2017). Thomson Reuters Eikon - Natural Gas Market Data.

Ejarque, J. M. (2011). Evaluating the economic cost of natural gas strategic storage restrictions. Energy Economics, 33(1):44-55.

ENTSO-G (2015). Capacity map of the European natural gas network. Retrieved from: http://www.entsog.eu/maps/transmission-capacity-map 
ENTSO-G (2017). ENTSOG Union-Wide Security of Supply Simulation Report. Retrieved from: https://www.entsog.eu/security-of-supply-simulation

European Commission (2014a). European Energy Security Strategy. Retrieved from http://eurlex.europa.eu/legal-content/EN/TXT/PDF/?uri=CELEX:52014DC0330\&from=EN.

European Commission (2014b). Communication from the Commission to the European Parliament and the Council on the short term resilience of the European gas system - preparedness for a possible disruption of supplies from the East during the fall and winter of 2014/2015. Retrieved from https://ec.europa.eu/energy/sites/ener/ files/documents/2014_stresstests_com_en.pdf

European Commission (2015). The role of gas storage in in- ternal market and in ensuring security of supply. Retrieved from http://ec.europa.eu/energy/en/studies/role-gas-storage-internal-market-andensuring-security-supply.

Eurostat (2015). Supply of gas - monthly data. Retrieved from http://ec.europa.eu/eurostat/web/energy/data/database

Gas Infrastructure Europe (2015a). GIE gas storage map. Retrieved from: http://www.gie.eu/index.php/maps-data/gse-storage-map

Gas Infrastructure Europe (2015b). GIE lng map. Retrieved from: http://www.gie.eu/index.php/maps-data/lng-map

Holz, F. (2009). Modeling the European natural gas market - static and dynamic perspectives of an oligopolistic market. German Institute for Economic Research (DIW).

Holz, F., Richter, P. M., and Egging, R. (2013). The role of natural gas in a low-carbon Europe: Infrastructure and regional supply security in the global gas model. DIW Berlin Discussion Paper.

IEA (2015a). Gas trade flows in Europe. Retrieved from https://www.iea. org/gtf/.

IEA (2015b). Natural Gas Information 2015. Organization for Economic Cooperation and Development, Paris.

IEA (2015c). World Energy Outlook 2015. Organization for Economic Cooperation and Development, Paris.

JODI (2015). Joint organizations data initiative (JODI) gas. Retrieved from https://www.jodidata.org/gas/

Le Coq, C. and Paltseva, E. (2009). Measuring the security of external energy supply in the European Union. Energy Policy, 37(11):4474-4481.

Lochner, S. (2011). Identification of congestion and valuation of transport infrastructures in the European natural gas market. Energy, 36(5):2483- 2492.

Morbee, J. and Proost, S. (2010). Russian gas imports in Europe: How does Gazprom reliability change the game? The Energy Journal, 31(4):79-109.

Neumann, A. and von Hirschhausen, C. (2015). Natural gas: An overview of a lower-carbon transformation fuel. Review of Environmental Economics and Policy, 9(1):64-84. 
Neumann, A., Rüster, S., and von Hirschhausen, C. (2015). Long-term con- tracts in the natural gas industry: Literature survey and data on 426 contracts (1965-2014). Data Documentation, DIW 77, Berlin.

Neumann, A., Viehrig, N., and Weigt, H. (2009). InTraGas - a stylized model of the European natural gas network. Dresden University of Technology - Resource Markets Working Paper WP-RM-16.

OME (2002). Assessment of internal and external gas supply options for the eu - executive summary. Technical report, Observatoire Mediterranéen de l'Energie Sophia-Antipolis, Study for the European Union.

Paltsev, S. (2014). Scenarios for Russia's natural gas exports to 2050. Energy Economics, 42:262 270.

Richter, P. M. and Holz, F. (2015). All quiet on the Eastern front? disruption scenarios of Russian natural gas supply to Europe. Energy Policy, 80:177- 189.

Ruble, I. (2017). European Union energy supply security: The benefits of natural gas imports from the Eastern Mediterranean. Energy Policy, 105: 341-353.

Seeliger, A. (2006). Entwicklung des weltweiten Erdgasangebots bis 2030: eine modellgestützte Prognose der globalen Produktion, des Transports und des internationalen Handels, sowie eine Analyse der Bezugskostensituation ausgewählter Importnationen, Volume 61. Oldenburg Industrieverlag.

Stern, J. (2002). Security of European natural gas supplies. London, the Royal Institute of International Affairs, 7(5).

Zwart, G. and Mulder, M. (2006). NATGAS: A model of the European natural gas market. Technical report, CPB Netherlands Bureau for Economic Policy Analysis. 


\section{Appendix}

In the following we provide an overview on sensitivities on the underlying assumtions of the stratetgic storage assessment presented in Section 5.2.1; namely the costs of storage the definition of the strategic storage rules.

\section{Cost of storage}

For this sensitivity analysis, we run the model with a modified formulation of the storage cost function, where the holding of one unit of gas in storage induces a cost at each time period. For this, we multiply the storage level with a cost factor. In order to keep the results comparable, we assume that injection and withdrawal do not create additional costs and divide the so far assumed cost factor by five (thus assuming that average number of storage cycle per year is slightly greater than one). Looking at Table 11 one notices that both the lost load ratio and the increase in consumer expenses are rather close to their respective value with the former cost formulation. The missing supply resulting from the crisis is slightly larger than the former one, explained notably by the light drop in storage fullness that derives from the new cost structure. On the other hand, the growth in consumer expenses stay slightly below the former values. Overall, one does not notices significant differences in the main results with the alternative cost formulation.

\section{Table 11: Results for cost sensitivity}

\begin{tabular}{c|c|c|c} 
Sto. oblig. & Av. fullness & LL / demand. & Cons. exp. \\
\hline $0 \%$ & $65 \%$ & $13.7 \%$ & - \\
$10 \%$ & $70 \%$ & $9.7 \%$ & $0.8 \%$ \\
$20 \%$ & $76 \%$ & $5.5 \%$ & $2.4 \%$ \\
$30 \%$ & $80 \%$ & $3.7 \%$ & $4.9 \%$ \\
$40 \%$ & $82 \%$ & $2.4 \%$ & $8.1 \%$ \\
$50 \%$ & $86 \%$ & $1.5 \%$ & $11.1 \%$ \\
$60 \%$ & $91 \%$ & $0.5 \%$ & $13.8 \%$ \\
$70 \%$ & $96 \%$ & - & $16.7 \%$ \\
$80 \%$ & $97 \%$ & - & $19.9 \%$ \\
$90 \%$ & $100 \%$ & - & $24.8 \%$ \\
\hline
\end{tabular}

Average fullness of storage in relation to maximal storage capacity, ratio of lost load over demand during the crisis months, increase in consumer expense under normal market conditions induced by the storage obligation.

\section{Storage holding obligation}

We further test two different formulations of the policy. In the first one, the storage obligation is formulated on the aggregated level. Instead of each country having to hold a certain percentage of their storage capacity, we assume that a certain percentage of the yearly total European consumption must be held in storage somewhere in Europe, regardless in which country. This naturally leads to a higher amount of stored gas, as now also demand from countries without storage factors into the obligation. ${ }^{16}$

\footnotetext{
${ }^{16}$ Assuming an European storage obligation defined on the overall storage capacity - and therefore equivalent to the country specific obligation approach - should lead by definition to at least the same, likely better results, as the model will have more
} 
One can gather from Table 12 how the first few iterations of this alternative formulation only have a modest impact on the average storage fullness. The policy's impact only kicks in at approximately $15 \%$, while it induces full storage at roughly $20 \%$ already. The level of storage required for the policy to be effective in terms of security of supply, e.g. $20 \%$, induces larger rise in consumer expenses than with the former formulation. Hence, an aggregated approach seems less efficient than the previous one.

\section{Table 12: Results for aggregated storage obligation}

\begin{tabular}{c|cc|c} 
Sto. oblig. & Av. filling & LL / demand. & Cons. exp. \\
\hline $0 \%$ & $72 \%$ & $11.2 \%$ & - \\
$2.5 \%$ & $73 \%$ & $9.3 \%$ & $0.8 \%$ \\
$5 \%$ & $73 \%$ & $7.9 \%$ & $3.5 \%$ \\
$7.5 \%$ & $73 \%$ & $5.6 \%$ & $6.6 \%$ \\
$10 \%$ & $70 \%$ & $4.9 \%$ & $9.8 \%$ \\
$12.5 \%$ & $73 \%$ & $4.1 \%$ & $12.7 \%$ \\
$15 \%$ & $78 \%$ & $3.2 \%$ & $15.6 \%$ \\
$17.5 \%$ & $86 \%$ & $1.6 \%$ & $19.8 \%$ \\
$20 \%$ & $97 \%$ & $0.2 \%$ & $24.2 \%$ \\
$22.5 \%$ & $99 \%$ & - & $29.2 \%$ \\
\hline
\end{tabular}

Average filling of storage in relation to maximal storage capacity, ratio of lost load over demand during the crisis months, Increase in consumer expense under normal market conditions induced by the storage obligation.

As a second step, we test an alternative formulation which relaxes the year-round obligation of storage holding and introduces additional flexibility The policy is formulated as follow: each country possessing gas storage must hold at the beginning of the winter (November) a certain percentage of its domestic winter demand or, if this exceeds its capacity, the same percentage of its storage capacity. Contrarily to the normal formulation, countries are hereby allowed to use their strategic reserves during the winter, bearing in mind they must have their storage refilled by the beginning of the next winter.

Looking at the benefits of the policy, although the first few iterations deliver insignificant changes, one notices that roughly starting from a $40 \%$ limit, the welfare reduction amounts to similar values as with the regular formulation. On the other hand, the induced increase in consumer expenses is significantly smaller. For example, a level of $50 \%$ results in a $5 \%$ increase in consumer expenses, whereas the same level induces a $12 \%$ rise for the previous formulation, while both lost load ratios are at comparable level. Hence, for a similar benefit, this alternative formulation seems to create smaller negative welfare impacts. This is to be explained by the flexibility provided to the countries which must not hold the strategic reserve unused, but might actually withdraw it during the winter season and feed it back to the market.

flexibility to distribute the same amount of stored gas. The main challenge for a joint approach therefore lies in the definition of a appropriate target value. 
A likely similar result could be obtained by gradually freeing up the strategic storage over the winter months when no crisis occurs (i.e. allowing $25 \%$ of the stored gas to be used after December, antoher $25 \%$ after January and so on).

Table 13: Results for demand related storage obligation

\begin{tabular}{c|cccc} 
Sto. oblig. & Av. filling & LL / demand. & Cons. exp. \\
\hline $0 \%$ & $71.5 \%$ & $10.9 \%$ & - \\
$10 \%$ & $73.3 \%$ & $10.9 \%$ & - \\
$20 \%$ & $74.0 \%$ & $10.9 \%$ & - \\
$30 \%$ & $75.5 \%$ & $8.5 \%$ & $0.8 \%$ \\
$40 \%$ & $80.1 \%$ & $4.0 \%$ & $3.3 \%$ \\
$50 \%$ & $83.1 \%$ & $2.2 \%$ & $4.2 \%$ \\
$60 \%$ & $85.7 \%$ & $0.6 \%$ & $4.9 \%$ \\
$70 \%$ & $87.3 \%$ & - & $5.5 \%$ \\
$80 \%$ & $88.5 \%$ & - & $5.9 \%$ \\
$90 \%$ & $89.0 \%$ & - & $6.0 \%$ \\
\hline
\end{tabular}

Average filling of storage in relation to maximal storage capacity, ratio of lost load over demand during the crisis months, increase in consumer expense under normal market conditions induced by the storage obligation. 